\title{
GERMINAÇÃO DE SEMENTES DE Melanoxylon brauna schott EM DIFERENTES TEMPERATURAS ${ }^{1}$
}

Andressa Vasconcelos Flores², Eduardo Euclydes de Lima e Borges ${ }^{3}$, Valéria Monteze Guimarães ${ }^{4}$, Glauciana da Mata Ataíde ${ }^{5}$ e Renato Vinícius Oliveira Castro ${ }^{6}$

\begin{abstract}
RESUMO - Os objetivos deste trabalho foram investigar o efeito da temperatura sobre a germinação de sementes de Melanoxylon brauna e identificar as temperaturas cardinais de germinação, bem como avaliar a eficiência do teste de condutividade elétrica para determinação das temperaturas cardinais. Para tanto, foram realizados três ensaios. No primeiro, foi feita a determinação das curvas de embebição, em cada temperatura $(5,10,15,20,25,30,35$, 40 e $45^{\circ} \mathrm{C}$ ); as sementes foram pesadas a cada $2 \mathrm{~h}$, por um período de $12 \mathrm{~h}$ e após a cada $12 \mathrm{~h}$ até a protrusão radicular de $50 \%$ das sementes, ou até 120 h quando na ausência de germinação. No segundo ensaio, para identificar as temperaturas cardinais, as sementes foram mantidas sob cada temperatura, por 10 dias, em câmara tipo BOD, sob luz constante. No terceiro ensaio, foi realizado um teste de condutividade elétrica com as sementes incubadas por períodos de 24, 48 e 72 h de embebição em cada uma das temperaturas e, em seguida, colocadas em erlenmeyers com $75 \mathrm{~mL}$ de água deionizada a $25^{\circ} \mathrm{C}$, por $24 \mathrm{~h}$, para posterior leitura da condutividade elétrica. É mais criterioso recomendar faixas de temperaturas para germinação do que temperaturas pontuais. As temperaturas cardinais (teóricas) para a característica porcentagem de germinação são: $12,3{ }^{\circ} \mathrm{C}$ - mínima, $30,0^{\circ} \mathrm{C}$ - ótima (teórica) e $42,7{ }^{\circ} \mathrm{C}$ - máxima. As faixas de temperatura considerando todas as variáveis investigadas são: $12,1-12,6^{\circ} \mathrm{C}$ (mínima); $30,0-35,8^{\circ} \mathrm{C}$ (ótima); e 42,4-43, $0^{\circ} \mathrm{C}$ (máxima). A espécie apresenta grande amplitude de germinação com relação à temperatura, sendo verificada a germinação na faixa de 12,0 a $42,0^{\circ} \mathrm{C}$. O teste de condutividade elétrica foi eficiente para avaliar o efeito da temperatura sobre as sementes e, nesse teste, a temperatura ótima é de $27,0^{\circ} \mathrm{C}$..
\end{abstract}

Palavras-chave: Embebição; Condutividade elétrica; Sementes florestais.

\section{GERMINATION OF Melanoxylon brauna schott SEEDS IN DIFFERENT TEMPERATURES}

\begin{abstract}
The objective of this study was to investigate the effect of temperature on the germination of Melanoxylonbrauna seeds and identify cardinal temperatures for germination, as well as to evaluate the efficiency of the electrical conductivity test to determine the cardinal temperatures. Therefore, three testswere performed. In the first test, the determination of imbibition curves was performed at each temperature $\left(5,10,15,20,25,30,35,40\right.$ and $\left.45^{\circ} \mathrm{C}\right)$, the seeds were weighed every two hours for a period of 12 hours and after every 12 hours until the root protrusion of $50 \%$ of the seeds, or 120 hours when there was no germination. In the second test, to identify the cardinal temperatures, seeds were kept under each temperature for a period of 10 days in DBO under constant light. In the third test, an electrical conductivity test was performed with the seeds incubated for 24, 48 and 72 hours of imbibition in each of the temperatures, and then were placed inerlenmeyer flasks with $75 \mathrm{~mL}$ of deionized water at $25^{\circ} \mathrm{C}$ for 24 hours for subsequent reading of the electrical conductivity. It is more judicious to recommend temperature ranges for germination than punctual temperatures. The cardinal temperatures (theoretical) for the characteristic germination rates are: $12.3^{\circ} \mathrm{C}$ - minimum
\end{abstract}

\footnotetext{
${ }^{1}$ Recebido em 12.12.2011 aceito para publicação em 22.09.2014

${ }^{2}$ Pós-doutoranda em Ciência Florestal, Departamento de Engenharia Florestal, Universidade Federal de Viçosa - UFV, Viçosa, MG - Brasil. E-mail: <andressafloressm@yahoo.com.br>.

${ }^{3}$ Departamento de Engenharia Florestal, Universidade Federal de Viçosa, Viçosa, MG - Brasil. E-mail: <elborges@ufv.br>.

${ }^{4}$ Laboratório de Sequenciamento de DNA - BIOAGRO, Universidade Federal de Viçosa - UFV, Vicosa, MG - Brasil. E-mail: <vmonteze@ufv.br>.

${ }^{5}$ Programa de Pós-Graduação em Ciência Florestal, Departamento de Engenharia Florestal, Universidade Federal de Viçosa - UFV, Viçosa, MG - Brasil. E-mail: <glaucianadamata@yahoo.com.br>.

${ }^{6}$ Doutorado em Ciência Florestal, Departamento de Engenharia Florestal, Universidade Federal de Viçosa - UFV, Viçosa, MG - Brasil. E-mail: <castrorvo@ymail.com>.
} 


\begin{abstract}
$-30.0^{\circ} \mathrm{C}$ optimal (theoretical) and $42.7^{\circ} \mathrm{C}$ maximun. The temperature ranges considering all the variables investigated were: 12.1 to $12.6^{\circ} \mathrm{C}$ (minimum); 30.0-35. $8^{\circ} \mathrm{C}$ (optimum) and $42.4-43.0^{\circ} \mathrm{C}$ (maximum). The specie has a wide range of germination with respect to temperature, and germination was observed in the temperature range from 12.0 to $42.0^{\circ} \mathrm{C}$. The electrical conductivity test was efficient to evaluate the effect of temperature onseeds and according to this test the optimal temperature is $27.0^{\circ} \mathrm{C}$.
\end{abstract}

Keywords: Imbibition; Electrical conductivity; Forest seeds.

\section{INTRODUÇÃO}

A temperatura atua no processo germinativo, determinando a velocidade e a porcentagem de germinação das sementes. A ação ocorre pelas modificações na estrutura e conformação das moléculas, em especial proteínas e lipídeos, envolvidos em reações químicas durante a germinação, podendo afetar a absorção de água e as reações bioquímicas que regulam o metabolismo envolvido na germinação, além de alterações na estrutura de membranas (BEWLEY; BLACK, 1994).

A faixa de temperatura na qual as sementes podem germinar é característica de cada espécie, podendo variar entre as várias espécies. A temperatura ótima de germinação propicia a máxima porcentagem de germinação no menor tempo, enquanto sob temperaturas mínima e máxima a minoria das sementes germina (BEWLEY; BLACK, 1994). A faixa de temperatura adequada para germinação de sementes de Cedrela odorata encontra-se entre 25 e $30^{\circ} \mathrm{C}$ (ANDRADE; PEREIRA, 1994); para Dimorphandramollis, foi 30 a $35^{\circ} \mathrm{C}$ (PACHECO et al., 2010), para Myracrodruon urundeuva a faixa ótima foi de 20 a $30{ }^{\circ} \mathrm{C}$ (SILVA et al., 2002) e de 15 a $20^{\circ} \mathrm{C}$ para Marcetia taxifolia (SILVEIRA et al., 2004). Para a espécie Tabebuia aurea, Cabral et al. (2003) verificaram que a germinação ocorre dentro de ampla faixa de temperatura, sendo as temperaturas cardinais para o processo germinativo: $20^{\circ} \mathrm{C}$ (mínima), $35^{\circ} \mathrm{C}$ (ótima) e $40^{\circ} \mathrm{C}$ (máxima). Algumas espécies necessitam ainda de temperaturas alternadas para sua germinação(CETNARSKIFILHO; NOGUEIRA, 2005). Porém, para a maioria das sementes florestais a temperatura ótima é constante e situa-se entre 15 e $30^{\circ} \mathrm{C}$. Isso significa que o caráter adaptativo pode propiciar alta capacidade de estabelecimento das espécies no campo, aumentando, assim, a chance de sobrevivência, em comparação com as espécies que apresentam estreita faixa de temperatura para germinar (TOWNSEND; MACGINNIES, 1972; LABOURIAU, 1983).

Revista Árvore, Viçosa-MG, v.38, n.6, p.1147-1154, 2014
As sementes constituem a via mais utilizada para propagação das sementes de M. brauna. No entanto, a amplitude de temperatura em que ocorre a germinação e as consequências sobre a fisiologia das sementes não são conhecidas. Diante disso, os objetivos deste trabalho foram investigar as implicações da temperatura sobre a fisiologia de sementes de Melanoxylon brauna e identificar as temperaturas cardinais de germinação para a espécie, além de verificar a eficiência do teste de condutividade elétrica para determinação das temperaturas cardinais.

\section{MATERIAL E MÉTODOS}

\subsection{Material vegetal e beneficiamento}

As sementes de Melanoxylon brauna foram colhidas em 10 árvores-matrizes na cidade de Leopoldina, MG, em setembro de 2010. Após a colheita, os frutos foram secos ao sol até a sua abertura, quando as sementes continham, aproximadamente, $13 \%$ de teor de água. Durante o beneficiamento, foram eliminadas as sementes imaturas, deterioradas ou danificadas. Em seguida, foram armazenadas em tambores de fibra, a $5^{\circ} \mathrm{Ce} 60 \%$ de umidade relativa do ar, por aproximadamente 30 dias.

\subsection{Determinação da curva de embebição}

Para determinação da curva de embebição, as sementes foram pesadas em balança analítica digital com precisão de 0,0001 g. Em seguida, foram distribuídas em rolos de papel germitest e postas em câmara tipo BOD sob luz constante, proporcionada por quatro lâmpadas de $20 \mathrm{~W}$, tipo luz do dia, os quais foram regulados nas seguintes temperaturas: $5,10,15,20$, $25,30,35,40$ e $45^{\circ} \mathrm{C}$, permanecendo por $240 \mathrm{~h}$ ou 10 dias. Posteriormente, as sementes foram pesadas a cada $2 \mathrm{~h}$ pelo período de $12 \mathrm{~h}$ e, após, a cada $12 \mathrm{~h}$ até a protrusão radicular $(2 \mathrm{~mm})$ de $50 \%$ das sementes ou, quando na ausência da protrusão, até $120 \mathrm{~h}$ ou cinco dias. O ganho de peso (GP) das sementes foi calculado de acordo com a fórmula: $\mathrm{GP}=\left(\frac{\mathrm{Pf}-\mathrm{Pi}}{\mathrm{Pi}}\right) \times 100$, em que 
$\mathrm{Pf}=$ peso final (ganho de umidade a cada período de embebição); e Pi = peso inicial das sementes antes da embebição. Foram utilizadas cinco repetições de 20 sementes para cada temperatura. Os gráficos foram elaborados no programa Sigma Plot 11.0.

\subsection{Determinação das temperaturas cardinais}

Na determinação das temperaturas cardinais de germinação, as sementes foram semeadas em rolos de papel germitest umedecidos com água destilada e embalados em sacos plásticos fechados com atilhos de borracha para evitar a dessecação, sendo submetidos às temperaturas constantes citadas anteriormente, sob as mesmas condições do teste de germinação (10 dias em câmara tipo BOD, sob luz constante, proporcionada por quatro lâmpadas de $20 \mathrm{~W}$, tipo luz do dia). Foram consideradas germinadas as sementes que emitiram radícula $(2 \mathrm{~mm})$. O número de sementes germinadas foi avaliado diariamente. O reumedecimento do substrato foi feito sempre que necessário.

A partir do número de sementes germinadas, foram calculados a porcentagem de germinação $-\mathrm{G} \%$; o índice de velocidade de germinação - IVG (MAGUIRE, 1962); e a velocidade média de germinação $-\mathrm{V}_{\mathrm{m}}$ (LABOURIAU; VALADARES, 1976; LABOURIAU, 1983). Odelineamento experimental utilizado foi o inteiramente casualizado e em cada temperatura, realizadas cinco repetições de 20 sementes.

Os dados, com exceção da frequência relativa, foram submetidos à análise de variância e regressão não linear a 5\% de significância, utilizando-se a função Weibull de dois parâmetros para a característica G\% e IVG, sendo estas ajustadas pelo método da máxima verossimilhança, empregando-se o algoritmo desenvolvido por Gove e Fairwheater (1989) e a função Polinomial para a característica $\mathrm{V}_{\mathrm{M}}$, que foi ajustada no software Curve Expert versão 1.3.

\subsection{Teste de condutividade elétrica}

Para o teste de condutividade elétrica (CE), as sementes, sem danos aparentes, foram pesadas em balança digital de precisão $0,0001 \mathrm{~g}$, colocadas em rolos de papel e mantidas por 24, 48 e $72 \mathrm{~h}$ de embebição em cada uma das temperaturas citadas anteriormente. Em seguida, foram colocadas em erlenmeyers com $75 \mathrm{~mL}$ de água deionizada a $25^{\circ} \mathrm{C}$, por $24 \mathrm{~h}$. A CE do lixiviado foi determinada, utilizando-se condutivímetro MICRONAL, modelo B 330, eletrodo com constante
1,0 , conforme procedimento descrito por Woodstock (1973), e o resultado foi expresso em $\mu \mathrm{S} \mathrm{cm}^{-1} \mathrm{~g}^{-1}$. Utilizaram-se as cinco repetições de 20 sementes para cada temperatura em cada tempo de embebição. O delineamento experimental foi o inteiramente casualizado em esquema fatorial $3 \times 9$ (três tempos de embebição e nove temperaturas) e os resultados, submetidos às análises de variância e regressão, utilizando-se o programa SAS.

\section{RESULTADOS}

Conforme representado nas curvas de embebição (Figura 1), a temperatura atuou diretamente sobre a velocidade de embebição e na quantidade final de água absorvida pelas sementes. A embebição acelerou com o aumento da temperatura, obtendo-se maior quantidade final de água nos tratamentos com temperaturas mais altas. Na temperatura de $45^{\circ} \mathrm{C}$, em que se observou início de deterioração das sementes, ocorreu ganho de peso de aproximadamente $120 \%$ nas primeiras $24 \mathrm{~h}$, enquanto a $5^{\circ} \mathrm{C}$ o ganho foi de aproximadamente $20 \%$ do peso inicial. Nessa e na temperatura de $10^{\circ} \mathrm{C}$, as curvas se mostram ascendentes, enquanto nas demais há tendência de início da fase II da germinação.

O efeito da temperatura na germinação de sementes de Melanoxylon brauna foi não linear, descrito pela função Weibull, em que se verificou o máximo percentual médio de germinação a $30{ }^{\circ} \mathrm{C}$ (Figura 2). No intervalo

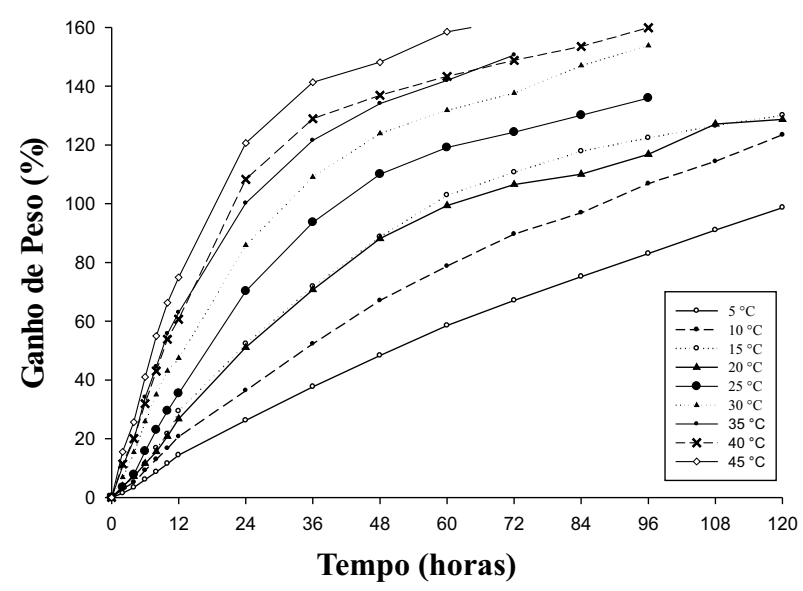

Figura 1 - Curvas de embebição de sementes de Melanoxylon brauna sob diferentes temperaturas.

Figure 1 - Imbibition curves of Melanoxylon brauna seeds under different temperatures.

Revista Árvore, Viçosa-MG, v.38, n.6, p.1147-1154, 2014

Revista Árvore, Viçosa-MG, v.38, n.6, p.1147-1154, 2014

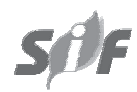




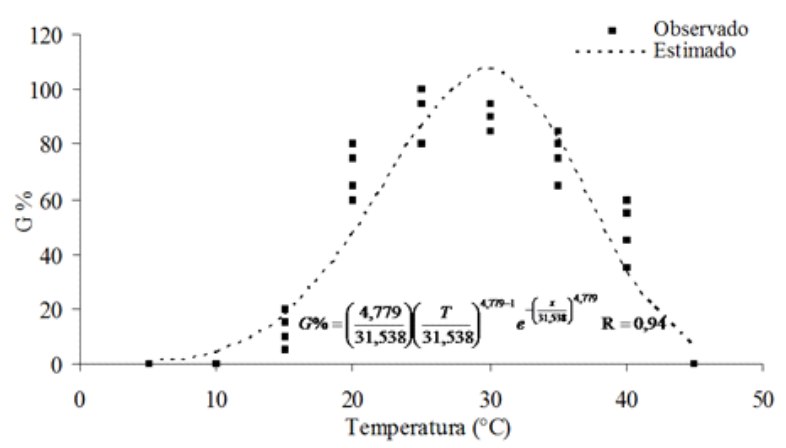

Figura 2 - Efeito de diferentes temperaturas sobre o percentual de germinação de sementes de Melanoxylon brauna. Em que G: germinação.

Figure 2-Effect of different temperatures on the germination percentile of Melanoxylon brauna seeds. In which G: germination.

das temperaturas de 20 a $40{ }^{\circ} \mathrm{C}$, a porcentagem de $50 \%$ de germinação ocorreu com $96 \mathrm{~h}$. Nas temperaturas de 5,10 , e $45^{\circ} \mathrm{C}$, não foram observadas protrusões de radícula. Na temperatura de $15^{\circ} \mathrm{C}$, as sementes não atingiram $50 \%$ de germinação durante o período de observação. As temperaturas mínima, ótima e máxima foram 10; 0,30; e $45,0^{\circ} \mathrm{C}$, respectivamente (Figura 2).

As temperaturas cardinais para o IVG foram de $12,1^{\circ} \mathrm{C}$ (mínima), $33,1^{\circ} \mathrm{C}$ (ótima) e $42,4{ }^{\circ} \mathrm{C}$ (máxima) (Figura $3 \mathrm{~A}$ ) e, com relação à $\mathrm{V}_{\mathrm{M}}$, as temperaturas encontradas foram de $12,6^{\circ} \mathrm{C}$ (mínima), $35,8^{\circ} \mathrm{C}$ (ótima) e $43,0^{\circ} \mathrm{C}$ (máxima) (Figura 3B).

A interação foi significativa entre a temperatura e o tempo com a condutividade (Figura 4). Para a temperatura, o comportamento foi quadrático, sendo verificados maiores valores de CE para baixas e altas temperaturas.

\section{DISCUSSÃO}

Parte do aumento da quantidade de água embebida se deve ao menor valor do potencial hídrico das sementes, o que determina o sentido do fluxo de água do ambiente para as sementes, independentemente da temperatura, que é próprio da fase I da embebição (BEWLEY; BLACK, 1994). A temperatura, por sua vez, exerce seu efeito por razões metabólicas e fluidez da água. Nesse caso, o aumento da temperatura torna a água mais fluida, permitindo que se movimente com mais facilidade do meio para as sementes. Como as enzimas têm parte de suas atividades influenciadas pela temperatura, é esperado
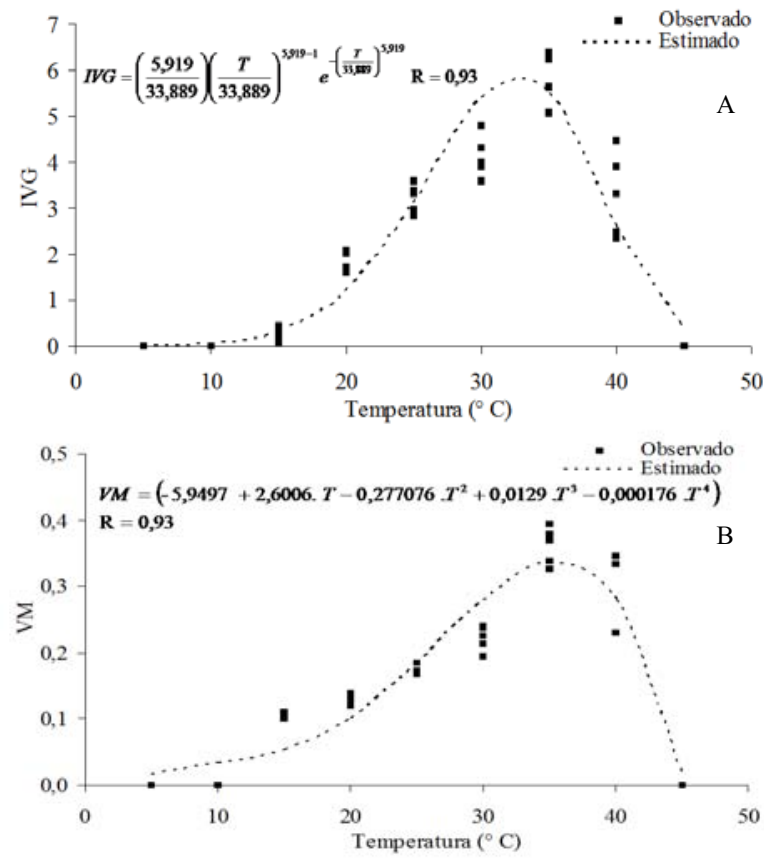

Figura 3 - Efeito de diferentes temperaturas sobre o índice de velocidade de germinação e velocidade média de germinação de sementes de Melanoxylon brauna. A: IVG: índice de velocidade de germinação; e B: VM: velocidade média de germinação.

Figure 3-Effect of different temperatures on the index of germination speedand medium germination speed of Melanoxylon brauna seeds. A:GSI: germination speed index; andB: MGS: medium germination speed.

que seu aumento reflita na maior atividade com consequente enfraquecimento da parede celular, permitindo que o turgor amplie o tamanho das células (WELBAUM; BRADFORD, 1990; CHEN; BRADFORD, 2000; NOGGLE; FITES, 2007). Nas temperaturas de 5 e $10^{\circ} \mathrm{C}$ (Figura 1), a maior permeabilidade das membranas celulares, por possíveis danos por frio, permite a saída de solutos para o apoplasto, tornando o potencial hídrico celular menos negativo, com consequente redução na taxa de embebição. Nesse caso, é de se supor que parte dos solutos osmoticamente ativos seja perdida para o meio, uma vez que a parede celular não tem capacidade de regular a movimentação de solutos.

Em relação à embebição das sementes, é possível classificá-las em três grupos, sendo o primeiro constituído pelo intervalo de 5 a $20^{\circ} \mathrm{C}$, o segundo de 20 a $35^{\circ} \mathrm{C}$ e o terceiro pelas temperaturas de 35 e $45^{\circ} \mathrm{C}$. No primeiro grupo, a porcentagem de germinação está em fase 


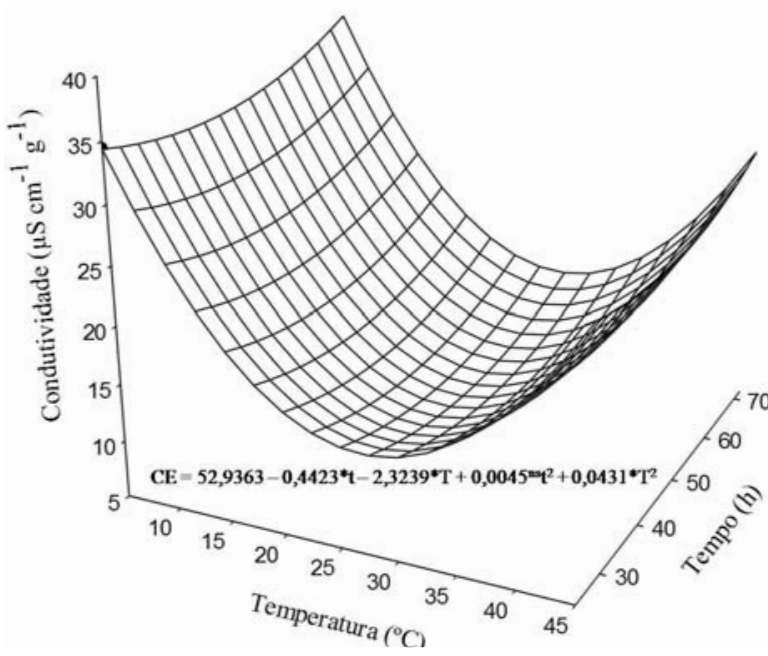

Figura 4-Condutividade elétrica em sementes de Melanoxylon braunas ubmetidas a diferentes temperaturas e tempos de embebição.

Figure 4-Electric conductivity in Melanoxylon brauna seeds submitted to different temperatures and imbibition times.

crescente, não sendo verificada a protrusão da radícula, a qual se inicia em $15^{\circ} \mathrm{C}$ (Figura 2). A faixa de temperatura de 20 a $35^{\circ} \mathrm{C}$ foi adequada para germinação das sementes, com porcentagens acima de $65 \%$; e no terceiro grupo, embora haja o máximo de embebição, a germinação é decrescente, pelos potenciais efeitos deletérios da temperatura sobre o metabolismo das células. Mesmo que na fase I da embebição não haja efeito relevante da temperatura, a manutenção das sementes em alta temperatura por curto período de tempo estimula a embebição, por efeito metabólico. Verificou-se que os parâmetros investigados indicam as temperaturas cardinais de modo semelhante, podendo inferir que é mais criterioso sugerir faixas de temperaturas do que temperaturas pontuais.

A redução da velocidade de germinação na temperatura de $25^{\circ} \mathrm{C}$ em relação a $35^{\circ} \mathrm{C}$ foi observada em sementes de Torresia acreana, contudo o percentual total de germinação a $35^{\circ} \mathrm{C}$ foi menor que a $25^{\circ} \mathrm{C}$ (ALBRECHT et al., 1986). Godoi e Takaki (2005) e Pacheco et al. (2010) também observaram esse padrão em sementes de Cecropia glaziovi e Dimorphandra mollis, respectivamente. Para Larcher (1986), a faixa ótima de temperatura para germinação de sementes de espécies de regiões tropicais está entre 20 e $35^{\circ} \mathrm{C}$, e estas apresentam maior dificuldade de se adaptarem a temperaturas baixas do que as altas, diminuindo a área de ocorrência natural dessas espécies. Em Miconia cinnamomifolia, sob temperatura mais baixa, o metabolismo é reduzido e a semente necessita de período mais longo até a protrusão radicular (AMARAL; PAULILO, 1992). No entanto, em temperaturas mais altas as velocidades de absorção de água e das reações químicas são maiores, e as sementes, até certo limite, têm o processo de germinação mais rápido (CARVALHO; NAKAGAWA, 2000). A temperatura ótima para germinação total é diferente da temperatura ótima para velocidade de germinação das sementes (CARVALHO; NAKAGAWA, 2000).

Na germinação sob temperaturas baixas $\left(5\right.$ a $\left.10^{\circ} \mathrm{C}\right)$ ou muito altas $\left(45^{\circ} \mathrm{C}\right)$, o metabolismo não é ativado de forma correta, e as reservas desdobradas na fase I e necessárias para o crescimento e desenvolvimento do embrião na fase III não são levadas até as regiões meristemáticas (BEWLEY; BLACK, 1994). Assim, não se verifica a finalização da germinação, e as sementes não passam da fase II. Nas temperaturas de 5 a $10^{\circ} \mathrm{C}$, podem ocorrer danos por frio, resultado de alterações na semipermeabilidade das membranas. Wang et al. (2006) verificaram maior absorção de água e maior perda de $\mathrm{K}^{+}$em sementes pequenas de Krascheninnikovia lanata, espécie arbustiva, quando a temperatura foi reduzida de 10 para $5{ }^{\circ} \mathrm{C}$. Nesse caso, a temperatura de mudança (Tm) na insaturação de ácidos graxos faz que haja vazamento até que a hidratação induza subida na $\mathrm{Tm}$ e resulte na reorganização da membrana, com consequente redução na liberação de solutos da célula (BADEA; BASU, 2009). Entretanto, sob temperatura mais alta, a semipermeabilidade é perdida pela incapacidade de recuperação das funções das membranas devido à completa desorganização da bicamada lipoproteica. Assim, a temperatura ótima para germinação total de Melanoxylon brauna foi de $30,0^{\circ} \mathrm{C}$ e a temperatura ótima para velocidade média de germinação, de 35,8 ${ }^{\circ} \mathrm{C}$. As temperaturas mínima e máxima, independentemente da característica avaliada, foram cerca de $12^{\circ} \mathrm{C} \mathrm{e} 42^{\circ} \mathrm{C}$, respectivamente. Isso demonstra a grande amplitude de germinação dessa espécie com relação à temperatura.

As temperaturas de 25,30 e $35^{\circ} \mathrm{C}$ favoreceram a sincronização da germinação de sementes de Melanoxylon brauna e apresentaram comportamento 
unimodal, ou seja, apenas um pico de germinação (dados não apresentados). Percebe-se o efeito da temperatura no deslocamento dos picos para a esquerda, com aumento da velocidade de germinação e, ao mesmo tempo, redução nas frequências relativas nas temperaturas de 35 e $40^{\circ} \mathrm{C}$, quando em ambas ocorreu também redução da germinação (Figura 2). A sincronização em determinada faixa ótima de germinação tem implícito o estabelecimento de maior número de plântulas, com aumento da possibilidade de sobrevivência de grande número de indivíduos, em caso de outros fatores adversos. A sincronização em faixa restrita de temperatura pode limitar o estabelecimento da espécie, pois a ocorrência de temperaturas fora dessa faixa ocasiona redução na germinação, tanto no maior tempo para estabelecimento da plântula e, consequentemente, maior exposição às adversidades do meio que poderiam comprometer o sucesso no estabelecimento, quanto na redução da viabilidade de grande parte do banco de sementes, quando em temperaturas mais altas.

O padrão de distribuição das frequências tem significado adaptativo, indicando compensação das condições desfavoráveis de temperatura por maior distribuição da germinação no tempo (LABOURIAU, 1983). Comportamento contrário aos observados neste trabalho, para sementes de Cecropia glaziovi, ou seja, a germinação distribuída no tempo ou na baixa sincronização, demonstrando a capacidade de adaptação dessa espécie, classificada como pioneira, às flutuações de temperatura (GODOI; TAKAKI, 2005). Esse comportamento também foi observado na germinação de sementes de Pterogyne nitens (NASSIF; PEREZ, 2000), Dalbergia nigra (FERRAZ-GRANDE; TAKAKI, 2001), Senna macranthera (CASSARO-SILVA, 2001), Myracrodruon urundeuva (SILVA et al., 2002) e Erythrina variegata (MATHEUS; LOPES, 2009).

O teste de condutividade elétrica (CE) baseia-se no princípio de que com o processo de deterioração ocorre a lixiviação dos constituintes celulares das sementes embebidas em água, devido à perda da integridade das membranas celulares (DUTRA et al., 2007). Assim, menores valores de CE indicam maior qualidade das sementes, como no caso, por exemplo, do efeito da temperatura sobre os sistemas de membranas. Diante disso, também pode ser sugerido que o teste de CE seja usado como bom indicador para investigar as implicações da temperatura sobre a fisiologia das sementes. Isso se deve ao fato de que, nas primeiras horas de embebição, a absorção de água ocorre com maior velocidade, não permitindo que a reidratação das membranas celulares aconteça na mesma velocidade, resultando em maior perda de constituintes celulares para o meio. Uma vez reidratadas, as membranas estão reorganizadas e a perda de constituintes celulares é menor, independentemente da temperatura. A temperatura de $27^{\circ} \mathrm{C}$ apresentou o menor valor de CE. Essa temperatura está próxima à temperatura ótima total de germinação de $30{ }^{\circ} \mathrm{C}$, indicando que provavelmente temperaturas próximas àquela estabelecida como ótima para a germinação deve promover a estabilidade térmica necessária para o funcionamento das membranas celulares. Para o fator tempo, o comportamento foi linear negativo, observando-se menores valores nos tempos mais longos de embebição.

\section{CONCLUSÕES}

As faixas de temperatura considerando todas as variáveis investigadas são: $12,1-12,6^{\circ} \mathrm{C}$ (mínima); 30,0 - 35, $8^{\circ} \mathrm{C}$ (ótima); e 42,4-43,0 ${ }^{\circ} \mathrm{C}$ (máxima).

$\mathrm{O}$ teste de C.E. é eficiente para avaliar o efeito da temperatura sobre as sementes, sendo por esse teste a temperatura ótima de $27,0^{\circ} \mathrm{C}$.

\section{REFERÊNCIAS}

ALBRECHT, J. M. F.; ALBUQUERQUE, M. C. L. F.; SILVA, V. S. M. Influência da temperatura e do tipo de substrato na germinação de sementes de cerejeira. Revista Brasileira de Sementes, v.8, n.1, p.49-55, 1986.

AMARAL, L. I. V.; PAULILO, M. T. F. Efeito da luz, temperatura, regulador de crescimento e nitrato de potássio na germinação de Miconia cinnamomifolia (DC.) Naudim. Insula, n.21, p.59-86, 1992.

ANDRADE, A. C. S.; PEREIRA, T. S. Efeito do substrato e da temperatura na germinação e no vigor de sementes de cedro - Cedrela odorata L. (Meliaceae). Revista Brasileira de Sementes, v.16, n.1, p.34-40, 1994.

BADEA, C.; BASU, S. K. The effect of low temperature on metabolism of membrane lipids in plants and associated gene expression.

Plant Omics Journal, v.2, n.2, p.78-84, 2009. 
BEWLEY, J. D.; BLACK, M. Seeds: physiology of development and germination. 2.ed. New York: Plenum Press, 1994. 445p.

CABRAL, E. L.; BARBOSA, D. C. A.; SIMABUKURO, E. A. Armazenamento e germinação de sementes de Tabebuia aurea (Manso) Benth. \& Hook. F. ex. S. Moore. Acta Botanica Brasilica, v. 17, n.4, p.609-617, 2003.

CARVALHO, N. M.; NAKAGAWA, J. Germinação de sementes. In: CARVALHO, N. M.; NAKAGAWA, J. Sementes: ciência, tecnologia e produção. 4.ed., Jaboticabal: FUNEP, 2000. p.128-166.

CASSARO-SILVA, M. Efeito da temperatura na germinação de sementes de manduirana (Senna macranthera (Collad.) Irwin et Barn. -

Caesalpiniaceae). Revista Brasileira de Sementes, v.23, n.1, p.92-99, 2001.

CETNARSKI FILHO, R.; NOGUEIRA, A. C. Influência da temperatura na germinação de diásporos de Ocotea odorifera (Vellozo) Rohwer (canela-sassafrás). Ciência Florestal, v.14, n.2, p.191-198, 2005.

CHEN, F.; BRADFORD, K. J. Expression of an expansin is associate with endosperm weakening during tomato seed germination. Plant Physiology, v.124, p.1265-1274, 2000.

DUTRA, A. S.; MEDEIROS FILHO, S.; DINIZ, F. O. Teste de condutividade elétrica em sementes de Senna siamea (Lam.) H. S. Irwin e Barneby. Revista Ciência Agronômica, v.38, n.3, p.280-285, 2007.

FERRAZ-GRANDE, F. G. A.; TAKAKI, M. Temperature dependent seed germination of Dalbergia nigra Allem (Leguminosae).

Brazilian Archives of Biology and Technology, v.44, n.4, p.401-404, 2001.

GODOI, S.; TAKAKI, M. Efeito da temperatura e a participação do fitocromo no controle da germinação de sementes de embaúba. Revista Brasileira de Sementes, v.27, n.2, p.87-90, 2005.

GOVE, J. H.; FAIRWEATHER, S. E. Maximumlikelihood estimation of Weibull function parameters using a general interactive optimizer and grouped data. Forest Ecology and Management, v.28, n.1, p.61-99, 1989.
LABOURIAU, L. G. Germinação das sementes. Washington: Secretaria-Geral da Organização dos Estados Americanos, 1983. 174p.

LABOURIAU, L. G.; VALADARES, M. E. B. On the germination of seeds of Calotropis procera (Ait.) Ait.f. Anais da Academia Brasileira de Ciências, v.48, n.2, p.263-284, 1976.

LARCHER, W. Ecofisiologia vegetal. São Paulo: EPU, 1986. 319p.

MAGUIRE, J. D. Speed of germination and in selection and evaluation from seeding emergence and vigor. Crop Science, v.2, n.2, p.176-177, 1962.

MATHEUS, M. T.; LOPES, J. C. Temperaturas cardinais para a germinação de sementes de Erythrina variegata L. Revista Brasileira de Sementes, v.31, n.3, p.115-122, 2009.

NASSIF, S. M. L.; PEREZ, S. C. J. G. A. Efeito da temperatura na germinação de sementes de amendoim-do-campo (Pterogyne nitens Tul.).

Revista Brasileira de Sementes, v.22, n.1, p.1-6, 2000 .

NOGGLE, G. R.; FITES, R. C. The mechanisms of chilling damage in germinating seeds. In: PACHECO, M. V. et al. Germination and vigor of Dimorphandra mollis Benth. seeds under different temperatures and substrates. Revista Árvore, v.34, n.2, p.205-213, 2010.

SILVA, L. M. M.; RODRIGUES, T. J.; AGUIAR, D. I. B. Efeito da luz e da temperatura na germinação de sementes de aroeira (Myracrodruon urundeuva Allemão). Revista Árvore, v.26, n.6, p.691-697, 2002.

SILVEIRA, F. A. O.; NEGREIROS, D.; FERNANDES, G. W. Influência da luz e da temperatura na germinação de sementes de Marcetia taxifolia (A. St.-Hil.) DC.

(Melastomataceae). Acta Botanica Brasilica, v. 18, n.4, p.847-851, 2004.

TOWNSEND, C. E.; MCGINNIES, W. J. Mechanical scarification of cicer milkvetch (Astragalus cicer L.) seed. Crop Science, v.12, n.4, p.392-394, 1972.

Revista Árvore, Viçosa-MG, v.38, n.6, p.1147-1154, 2014 
WANG, R.; BAI, Y.; LOW, N.H.; TANINO, K. Seed size variation in cold and freezing tolerance during seed germination of winterfat (Krascheninnikovia lanata) (Chenopodiaceae). Canadian Journal Botany, v. 84, n.1, p.49-59, 2006.

WELBAUM, G. E.; BRADFORD, K. J. Waters relations of seed development and germination in muskmellon (Cucumis melo L.): V. Water relations of imbibitions and germination. Plant Physiology, v.92, n.4, p.1046-1052, 1990.

WOODSTOCK, L. M. Physiological and biochemical of seed vigor. Seed Science and Technolology, v.1, n.1, p.127-157, 1973.

Revista Árvore, Viçosa-MG, v.38, n.6, p.1147-1154, 2014 